\title{
Vigencia del pensamiento de Maquiavelo sobre la guerra
}

\section{Validity of Machiavelli's Thought on War}

\author{
Federico Aznar Fernández-Montesinos ${ }^{1}$ \\ Analista del Instituto Español de Estudios Estratégicos \\ (España)
}

Recibido: 27-03-20

Aprobado: 25-05-20

\section{Resumen}

Maquiavelo es un precursor, también en lo que se refiere a la guerra. De hecho, se cumplen precisamente ahora 500 años de su gran clásico, Dell 'Arte della Guerra, que tanta influencia tuvo hasta el siglo XVII. Su postura estratégica se adelanta a Clausewitz al incidir sobre la naturaleza política de la guerra; y también a Max Weber al requerir para el Estado el monopolio de la violencia legítima. Su apuesta por la milicia en detrimento de los mercenarios fue prematura para su tiempo por más que sea concorde al modelo democrático.

Palabras-clave: Maquiavelo, guerra, política, El Príncipe, El Arte de la Guerra, mercenario, razón de Estado.

\begin{abstract}
Machiavelli's thought is a forerunner, even regarding warfare; in fact, we are now in the fifth centenary of his great classic Dell 'Arte della Guerra, which had such an influence until the XVII century. His strategic commitment is ahead of Clausewitz when considering the political nature of

\footnotetext{
${ }^{1}$ (faznfer@fn.mde.es) Capitán de Fragata de la Armada y profesor del Centro Superior de Estudios de la Defensa Nacional (CESEDEN). Es doctor en Ciencias Políticas por la Universidad Complutense de Madrid y Licenciado también en Ciencias Políticas por la UNED. Es autor de cuatro libros: Entender la guerra en el siglo XXI, La ecuación de la guerra, El papel de las Fuerzas Armadas marroquies en la vida política del Reino y Repensando el liderazgo estratégico además de editor de otros dos La guerra contra la violencia y Vulnerabilidad y Democracia en Iberoamérica. Es también autor de más de 200 artículos y documentos de investigación.
}

Araucaria. Revista Iberoamericana de Filosofia, Politica, Humanidades y Relaciones Internacionales, año $22, \mathrm{n}^{\circ} 44$. Segundo semestre de 2020. Pp. 359-385. ISSN 1575-6823 e-ISSN 2340-2199 https://dx.doi.org/10.12795/araucaria.2020.i44.17 
war; and even ahead of Max Weber in requiring for the State the monopoly of legitimate violence. His commitment to the militia to the detriment of the mercenaries was premature for his time but consistent with the democratic model.

Key-words: Machiavelli, War, Politics, The Prince, The art of warfare, Mercenary, State Reason.

\section{Sobre guerra y política}

La guerra es un tema recurrente en Maquiavelo toda vez que esta es la actividad política más relevante que pueda emprender un Estado. De hecho, este llega a firmar en uno de sus grandes clásicos, El Príncipe (1513): "Un príncipe no debe tener otro objeto, otro pensamiento, ni cultivar otro arte más que la guerra, el orden y disciplina de los ejércitos, porque es el único que se espera ver ejercido por el que manda"2. El capítulo XIV de la obra se titula precisamente "De las obligaciones del príncipe en lo concerniente al arte de la guerra".

En El arte de la guerra, un libro más tardío (1521), insiste en tales planteamientos. Es el único de sus trabajos que conoció publicado en vida. Y tuvo un gran éxito; durante el siglo XVI se hicieron 21 ediciones y, además de al español, como veremos, se tradujo al francés, alemán, inglés y latín. Y aún se citaba en el siglo XVII cuando la guerra ya había cambiado sensiblemente ${ }^{3}$.

Es esta obra deudora de un destierro que empezaba ya a ser prolongado. $\mathrm{Su}$ principal protagonista, Fabrizio Colonna, sostiene: “jamás he ejercido el arte militar como profesión, pues la mía es gobernar a mis ciudadanos y protegerlos; y para poder protegerlos, debo amar la paz y saber hacer la guerra"4.

De esta manera no se define como un condottiero y sí como gobernante; y, por tanto, como alguien obligado a conocer el arte de la guerra, pues "además de las otras calamidades que se atrae un príncipe que no entiende nada de guerra, hay la de no poder ser estimado de sus soldados, ni fiarse de ellos. El príncipe no debe cesar, pues, jamás, de pensar en el ejercicio de las armas, y en los tiempos de paz, debe darse a ellas todavía más que en los de guerra"5.

Fiel a esta idea, aborda particularmente su problemática en otros señeros trabajos como los Discursos sobre la primera década de Tito Livio (tres

\footnotetext{
${ }^{2}$ Maquiavelo, El Príncipe, Madrid, Espasa-Calpe, p. 32.

3 Félix Gilbert, "Maquiavelo: El Renacimiento del Arte de la Guerra" [en Peter Paret coord.: Creadores de la Estrategia Moderna, Ministerio de Defensa, Madrid, 1992], p. 38.

${ }^{4}$ Nicolás Maquiavelo, El arte de la guerra. Obras politicas de Nicolás Maquiavelo. Ed. Librería de la viuda de Hernando y Cia., 1895, p. 105.

${ }_{5}$ Nicolás Maquiavelo, El Príncipe, Espasa-Calpe, p. 32.
} 
volúmenes 1512-1517), donde dedica capítulos exclusivamente a esta cuestión. Esta igualmente tiene reflejo en su Historia de Florencia (1520-1525) así como en dos textos menores y oficiales: La causa de la Ordenanza militar y la Provisión de la Ordenanza (1505) en los que deja entrever su pensamiento. Es más, en estos últimos, y pese a su carácter administrativo, ya hablaba de justicia y armas como factores de fuerza del Estado, un tema que viene a ser el hilo central de su Príncipe.

Clausewitz, el intérprete de Napoleón y apóstol de la naturaleza política de la guerra, que suele ser habitualmente muy crítico con otros tratadistas, en el caso de Maquiavelo reconoció expresamente que "tenía buen sentido para analizar los temas militares"6.

$\mathrm{Y}$ es que, para el florentino, al igual que para el germano, la guerra no es solo una actividad militar, esto es, no es únicamente una sucesión de batallas. La historia nos dota hoy de múltiples ejemplos en que quien gana todas las batallas, acaba perdiendo la guerra (Vietnam, Argelia). A la contra, actos no sangrientos, por ejemplo, un embargo económico, pueden ocasionar más daños sobre un Estado que un ejercicio directo de violencia.

La guerra también puede ser vista como una Institución de Derecho Internacional público, como la más importante. Comenzaría con una declaración de guerra (que debería ser conforme al ius ad bellum), se desarrollaría de un cierto modo (ius in bello) y acabaría con un tratado de paz. Pero es un hecho que no es así.

También podría analizarse en términos de economía o incluso de religión, justicia, etc., pero no encontraríamos un patrón satisfactorio para explicar todos los casos posibles, porque la guerra es o puede ser un acto militar, jurídico, económico, religioso, ideológico, etc. No obstante, cualquier análisis que se haga en exclusiva desde esos planos es insuficiente y, por consiguiente, puede traducirse en peligrosas equivocaciones.

La guerra es una actividad inherentemente política y quien no emprenda su análisis desde esta perspectiva yerra gravemente. Es más, y en tanto que choque de poderes, no es una actividad inherentemente sangrienta, sino inherentemente política. Como dijera Bouthoul refiriéndose a la obra Historia de Florencia antes citada,

"las guerras del Renacimiento, la de aquella batalla de Anagni... en la que hubo una víctima, un muerto por caída de caballo, eran guerras, mientras que la matanza de millones de civiles polacos a manos de alemanes solo fue un simple crimen"7.

${ }^{6}$ Félix Gilbert, op. Cit., p. 41.

${ }^{7}$ G. Bouthoul, Tratado de Polemología. Ediciones Ejército, Madrid, 1984, p. 98. 
En cualquier caso, el pensamiento de Maquiavelo supera con creces las dimensiones en que quedaba encuadrada la guerra durante el Medievo al instalarla en lo político. Entonces, el carácter religioso la reducía a un acto de justicia, mientras su dimensión social restringía su ejecución a la nobleza. Maquiavelo dotó a la guerra de un nuevo marco interpretativo al considerarla una herramienta de la política, algo que superaba cualquier norma, código o ética.

Y es que en la guerra la política marca los fines, el para qué y la dota de su razón de ser, a fin de cuentas, es uno de sus instrumentos. Sin política, se torna absurda e irracional. La guerra como dialéctica de voluntades hostiles queda consignada como un debate sangriento y netamente político superando con ello de facto los corsés medievales. Es más, al decir de Clausewitz, y como todo acto político, incorpora su propio lenguaje y es siempre un ámbito de elección. La gramática de la guerra es la política.

El pensamiento de Maquiavelo, de modo precursor, se instala precisamente en esta línea. Es más, se le incluye en la escuela realista de las relaciones internacionales que, asentada con una concepción negativa del ser humano en tanto que la violencia es connatural con él, se basa en la desconfianza, es estatista y de política de poder. Su idea de la paz es negativa, sustentada sobre el equilibrio de las potencias militares ${ }^{8}$.

A esta línea pertenecerían pensadores como Tucídides, Ibn Jaldún, Hobbes, Clausewitz, Morgentthau, Kennan, Raymond Aron, Kissinger o los movimientos darwinistas que ven en la guerra el motor de la historia. Para los realistas, es un error evaluar la guerra desde la ética y, por tanto, justificarla desde el punto de vista de su justicia cuando no condenarla en nombre de aquella. La ética es superada por la política cuando se trata de analizar las relaciones internacionales. Desde esta perspectiva, no se pueden aplicar principios éticos a problemas políticos entre Estados ${ }^{9}$. Estamos en un estilo teórico sin concesiones al moralismo. Freund sostenía que desde el Renacimiento la política se hizo autónoma y se dotó de fronteras propias. Raymond Aron, en este sentido sostenía que la esencia del maquiavelismo consiste en "el primado de la observación sobre la ética". Su cinismo se explica porque los hombres temen saber cómo obran en realidad.

El maquiavelismo de la estrategia confunde fuerza con poder; y esa es una grave equivocación, porque el poder no es solo mensurable en términos militares, sino que es la suma de componentes culturales, económicos, ideológicos, etc., haciendo de tal significación un absurdo. Lo que determina el poder no es lo que este destruye, sino muy al contrario, lo que es capaz de

\footnotetext{
${ }^{8}$ Charles-Philippe David, La guerra y la paz. Icaria, Barcelona, 2008, p. 70.

9 Felipe Jiménez Pérez, "El materialismo y la Paz" en El Catoblepas, Revista Crítica del presente, $\mathrm{n}^{\mathrm{o}} 28,2004$, p. 27.
}

Araucaria. Revista Iberoamericana de Filosofia, Política, Humanidades y Relaciones Internacionales, año $22, \mathrm{n}^{\circ} 44$. Segundo semestre de 2020. Pp. 359-385. ISSN 1575-6823 e-ISSN 2340-2199 https://dx.doi.org/10.12795/araucaria.2020.i44.17 
construir. A la obsesión de Maquiavelo por conseguir el poder le falta su "para qué". La suya es una metodología falta del necesario proyecto; su realización demuestra quién tiene el poder, pues este realmente no pertenece a quien ejecuta, sino a quien diseña el proyecto.

Es más, la guerra es una actividad del espíritu, en la que lo decisivo es la voluntad, algo muy en relación con la virtù. Se está derrotado cuando se acepta tal cosa y nunca antes. Vencer es convencer sobre la inutilidad de la lucha; pretende que la parte contraria abandone cualquier expectativa $\mathrm{y}$, consecuentemente, acceda a una negociación que le permita satisfacer sus objetivos más relevantes.

Refiriéndose a esto, Maquiavelo llama en múltiples ocasiones a no comprometer a las tropas en una acción "sino cuando tengan esperanza de vencer". La guerra, y nos lo recuerda Maquiavelo con frecuencia, se gana antes de emprenderla. Las operaciones militares deben ser, si el trabajo de preparación es el adecuado, poco más que puro trámite. Los dados que se echan cuando se recurre a ella deben encontrarse ya cargados.

Tal cosa además debe hacerse por causas tasadas:

"Cuando le sea indispensable derramar la sangre de alguno, no deberá hacerlo nunca sin que para ello haya una conducente justificación y un patente delito. Pero debe entonces, ante todas cosas, no apoderarse de los bienes ajenos; porque los hombres olvidan más pronto la muerte de un padre que la pérdida de su patrimonio" 10 .

Y esta es norma general para el florentino, una ley de oro. Lo suyo es la praxis, la realidad. Así, con igual lógica,

\begin{abstract}
"quien se adueñe de un Estado debe meditar sobre todo el daño que le será preciso infligir, e infligirlo de golpe a fin de no tener que repetirlo cada día, pues el no tener que hacerlo infundirá calma a sus hombres y le permitirá ganárselos con favores. El que obra de otro modo por debilidad, o siguiendo malos consejos, está precisado siempre a tener la cuchilla en la mano; y no puede contar nunca con sus gobernados, porque ellos mismos, con el motivo de que está obligado a continuar y renovar incesantemente semejantes actos de crueldad, no pueden estar seguros con él. Por la misma razón que los actos de severidad deben hacerse todos juntos, y que dejando menos tiempo para reflexionar en ellos ofenden menos; los beneficios deben hacerse poco a poco, a fin de que se tenga lugar para saborearlos mejor"11.
\end{abstract}

Por esta razón Maquiavelo, y autores como Keegan, o el propio Clausewitz, en la misma lógica, opinan que las batallas para ser decisivas

${ }_{11}^{10}$ Maquiavelo, El Príncipe. Espasa-Calpe, p. 37.

11 Ibidem, p. 21.

Araucaria. Revista Iberoamericana de Filosofí, Política, Humanidades y Relaciones Internacionales, año 22, $\mathrm{n}^{\circ} 44$. Segundo semestre de 2020. Pp. 359-385. ISSN 1575-6823 e-ISSN 2340-2199 https://dx.doi.org/10.12795/araucaria.2020.i44.17 
deben tener tal grado de bajas que representen un choque psicológico total para el perdedor. De lo contrario, es inevitable el deseo de revancha. El progresivo aumento de tropas con que los norteamericanos trataron de resolver la guerra de Vietnam es un ejemplo de fracaso.

De hecho, el florentino, en este razonamiento, apuesta por actuaciones de gran impacto, antes que por otras graduales a las que el enemigo se vaya acostumbrando. Y llama al proceso contrario para las fuerzas propias, ir conociendo al enemigo poco a poco, pedagógicamente y sin espasmos.

Como sostiene en sus Discursos, las guerras deben ser cortas y decisivas. Esa fue precisamente la práctica de Napoleón y es la doctrina recogida por Ullman en el ensayo Conmoción y pavor: alcanzando la dominación rápida. Con ello, se pretende actuar sobre la voluntad, percepción y comprensión del adversario para reaccionar, aunque se mantiene el objetivo de destruir a las fuerzas enemigas, la clave se encuentra en impactar sobre estas de un modo tan contundente que la desorientación y el miedo se adueñen de su voluntad ${ }^{12}$. Para eso, y puesto que estamos ante una pugna de voluntades, recordando a Glucksmann, "aquel que no retroceda ante ningún derramamiento de sangre llevará ventaja sobre su adversario"13.

La obra de Maquiavelo está plagada de ejemplos de tal proceder. César Borgia es un maestro en este sentido.

\section{Paz y política}

La guerra incorpora una contradicción dialéctica y es que su objetivo es la paz, algo que solo se supera con la aceptación de que ambos términos pertenecen a la política, razón por la cual no entran en conflicto, como a primera vista parece, y cuentan hasta con espacios comunes y de complementariedad.

No obstante, la sacralización de las palabras y el dotarles de un sentido mítico hacen que pierdan su función real: gana la guerra quien hace aceptar su idea de paz.

En el siglo XXI no se trata ya de vencer, sino también de convencer, de vencer "con", es decir, de repensar la victoria y transformarla en un episodio común y de mutuo beneficio que, para más inri, sea aceptable para la comunidad internacional. La paz pasa por la desactivación del elemento discursivo del que se alimenta la guerra, de sus intangibles. La alta política es pedagogía.

\footnotetext{
${ }^{12}$ Aníbal Villalba Fernández, "Evolución del pensamiento estratégico," Monografía del CESEDEN núm. 99/2003, pp. 131 y ss.

13 André Glucksmann, El Discurso de la guerra. Editorial Anagrama, Barcelona, 1969, p. 22.
} 
Es más, podemos presentar una guerra como un conflicto entre dos ideas de paz y que a veces gana la paz más violenta. La concepción de Maquiavelo sobre la paz es un tipo de paz que Galtung definiría como negativa, un estado de transición entre guerras.

Maquiavelo, como siempre, nos muestra las contradicciones que se dan a nivel político, en la medida en que la política se eleva sobre aquellas y las somete. La lógica política es una lógica específica paradójica y de transformación que pone en evidencia la mutación del marco ético-operativo que se produce al pasar de lo particular-individual a lo general y de grupo. Así,

\begin{abstract}
"César Borgia pasaba por cruel, y su crueldad, sin embargo, había reparado los males de la Romaña, extinguido sus divisiones, restablecido en ella la paz y la lealtad. Si profundizamos bien su conducta, veremos que él fue mucho más clemente que lo fue el pueblo florentino, cuando para evitar la reputación de crueldad dejó destruir Pistoya" ${ }^{14}$.
\end{abstract}

La paz podría definirse, en un término amplio, como una transición y también como la ausencia de conflicto; pero la paz no es un estado en sí misma, sino algo que se elabora. La guerra, como concepto, es un término lleno, mientras que la idea de paz está vacía. Es un concepto vacío que conviene completar para que realmente signifique algo y describa una nueva situación política que es imprescindible entender y valorar como tal.

Una auténtica paz trasciende de la mera superación de la violencia, que es siempre un primer paso. La paz debe ir más allá de una mera y ambigua definición negativa dentro de la que cabe cualquier cosa. En clave positiva, se perfila como todo un proyecto pedagógico y de transformación a largo plazo que debe ser coherente con cada espacio social y que, por ello, precisa de bases sólidas, algo que Maquiavelo no capta.

Con todo, la paz ha sufrido, como ya se ha mencionado, todo un proceso de sacralización que la ha acabado por convertir en un término absoluto, un tótem, pero también en un cliché, en un bien en sí mismo ante el que es preciso prosternarse cuando alguien pronuncia la palabra, privando así a los analistas de cualquier sentido crítico al desarmarlos en nombre de lo políticamente correcto. Es más, parece que los conflictos del siglo XXI los gana quien es capaz de adueñarse de la palabra paz presentando su proyecto como una verdad natural que acaba con cualquier problema. Los que se oponen a ella son entonces enemigos de la paz.

Debe quedar claro que el objetivo de la guerra es la paz y no la justicia, un concepto perteneciente a otro plano diferente, como también el trabajo de Maquiavelo pone en valor según se ha visto con el proceder de César Borgia. Aunque también es cierto que, sin una cierta justicia para las partes, no cabe

\footnotetext{
${ }^{14}$ Maquiavelo, El Principe. Espasa-Calpe, p. 36.
} 
la paz. Podemos entonces considerar sensu contrario y fruto de la lógica paradójica, que la paz se asienta no tanto sobre la justicia, sino al revés, sobre la injusticia percibida y que siéndolo resulta tolerable para las partes. Maquiavelo expondrá múltiples ejemplos de tal cosa.

La idea de una guerra justa aúna dos términos que se sitúan en planos conceptuales diferentes: uno, la guerra, en el de la política; y otro, el de la justicia, en la ética o en el derecho, según se mire. La combinación de ambos términos es irresoluble y genera una suerte de bucle melancólico. ¿Se puede obtener justicia a través de una serie de actos injustos? ¿Dónde se encuentra la justicia en matar a un civil, por ejemplo, un lechero que no porta armas en el bando equivocado? Puede ser políticamente necesario y legal, pero no justo.

Maquiavelo se despreocupa de la relación entre justicia y política, sometiendo la primera a la segunda y poniendo ésta al servicio del interés general. De hecho, astutamente, permite atisbar ya en El príncipe una idea que recoge explícitamente en su Historia de Florencia: "solamente son justas las guerras que son necesarias; y son piadosas las armas cuando no hay esperanza fuera de ellas"15. Esta frase aparece también en el capítulo XXVI de El Príncipe y es una cita literal de Tito Livio ${ }^{16}$ referida a la guerra samnita y que es nada menos que la primera justificación moral de la guerra que se ha hecho en la historia de Occidente ${ }^{17}$. Su valor es, por ello, altísimo.

De esta manera se aúnan fines, medios y resultados en una suerte de ius post bellum que evalúa la justicia de un conflicto en relación con ellos $\mathrm{y}, a$ posteriori, resolviendo la paradoja conceptual que encarna la idea de guerra justa. Para ello hace de la guerra un instrumento útil para resolver las situaciones de bloqueo, utilizando como criterio de verdad y justicia, el resultado final.

\section{El arte de la guerra}

Su libro titulado El arte de la guerra (1521) entronca con un debate apostillado por Clausewitz. Para este la guerra "no pertenece al ámbito de las artes ni de las ciencias, sino que forma parte de la existencia social humana"18, aunque opina que la expresión "arte de la guerra" es más adecuada que "ciencia de la guerra' ${ }^{19}$.

$\mathrm{Y}$ es que la estrategia es un arte por la inmanejable cantidad de elementos que intervienen en su diseño, lo que hace muy difícil su concepción como ciencia por el papel que tiene la intuición o el pensamiento divergente. Como

\footnotetext{
15 Maquiavelo, Historia de Florencia, Libro V, capítulo VIII.

16 Tito Livio, Historia de Roma desde su fundación, IX, 1.

17 Antonio Hermosa, El Hombre tras los hechos. Ediciones Universitarias Athenaica, 2019, p. 179.

${ }^{18}$ Carl Von Clausewitz, De la Guerra T.I. Ministerio de Defensa, 1999, p. 268.

19 Díaz de Villegas, La guerra revolucionaria. Madrid, Ediciones Europa, 1963, p. 51.
} 
decía Bracque, respondiendo a Picasso: "yo encuentro, y a continuación busco". Estamos, al igual que en los naipes a los que el florentino también recurre, ante una habilidad que obedece a unos ciertos principios o normas, cuya observancia, por otra parte, no garantiza el éxito por más que lo haga más probable. No es un juego abierto de inteligencias como lo es el ajedrez, pues en los naipes intervienen la personalidad del jugador y la fortuna.

Esta obra tiene como protagonista a Fabrizio de Colonna, un famoso condotiero de Carlos V, quien comparece en la obra actuando como alter ego de Maquiavelo, admirando siempre las virtudes "romanas" del Ejército español y que, luego, en la traducción que hace Diego de Salazar al español, se convierte en Gonzalo Fernández de Córdoba, el Gran Capitán.

Maquiavelo, en esta ocasión y aun a pesar de declararse diletante en la materia, se adentra en problemas estratégicos de marcado carácter técnico y abstracto sobre los que resulta difícil pronunciarse tanto por lo inconcreto de su propuesta como por la dificultad de valorar a posteriori el estado del arte militar de la época y la eficacia de las armas.

La época que le tocó vivir a Maquiavelo, en los albores de la Edad Moderna, corresponde a eso periodos en los que la cultura china califica como interesantes. Es, por ello, un precursor también en lo que se refiere al pensamiento militar. La paulatina generalización de las armas de fuego transformará con su progresivo perfeccionamiento los modos de hacer la guerra ocupando un lugar central en ella.

El florentino se presenta, así como lo que el general Beaufre definía como intérpretes del momento: "uno de los elementos esenciales de la estrategia militar ha sido comprender más de prisa que el adversario las transformaciones de la guerra". En esa sensibilidad especial anida la victoria. Ello explica la vigencia del pensamiento de Maquiavelo: un éxito cuyos ecos llegan hoy en día.

Y es que lo que ha caracterizado a los grandes estrategas ha sido comprender mucho más deprisa que el contrario; han sabido captar las grandes mutaciones experimentadas por las sociedades erigiéndose en intérpretes del momento y, a veces, llegan a hacer olvidar que son las sociedades las auténticas protagonistas de los conflictos. Su mérito radica en disponer de un agudo sentido de la intuición que los ha convertido en catalizadores de unos acontecimientos, por lo demás, muchas veces inevitables.

Sin embargo y como reproche, Maquiavelo no atina a ver el fundamental papel de la artillería (y aun de las propias armas de fuego), capital ya desde la caída de Constantinopla en 1453 a manos de las tropas de Mehmet II. Y eso es un grave error, un fracaso de la capacidad de interpretación y la visión anticipadora de la que debe encontrarse dotada la mirada estratégica. También es cierto, y debe subrayarse, que su 
desarrollo distaba con mucho de alcanzar aún la precisión y fiabilidad que tendrían mucho más adelante.

La muerte, en 1526, por causa de un disparo de falconete de Juan de Médicis, conocido como Juan de las Bandas Negras, tendrá un notable impacto político y servirá para escenificar este cambio, así como para subrayar el igualitarismo intrínseco al nuevo modo de hacer la guerra. Este cambio de modelo sería recogido en la película de 2001 El oficio de las armas, de Ermanno Olmi.

Además, y a modo de crítica de El Arte de la Guerra, transformar las ideas sobre el papel en una actividad tan compleja tiene el mismo inconveniente de la "fricción" que denunciara Clausewitz para justificar cómo, lo que de ordinario es simple, en la práctica de la guerra se transforma en gravoso. La materialización de las ideas no es tarea en absoluto sencilla y Maquiavelo tiene muchas y además complejas.

En este sentido, el germano considera que "todo en la guerra es muy sencillo, pero lo más sencillo es difícil. Estas dificultades se amontonan y determinan una fricción que nadie que no haya visto la guerra puede representarse felizmente"20. Fricción que viene producida por la acción del enemigo, pero también por el azar, el miedo, las imprevisiones más simples... Pasar de las musas al teatro no es un ejercicio de magia, el papel lo aguanta todo. Napoleón lo decía claramente: "la guerra es ejecución".

Lo que sí queda claro es que la propuesta de Maquiavelo es una idealización, una mitificación del pasado tan característica del Renacimiento que ignora que la historia es evolución. Su propuesta de volver al mundo romano -se sirve para ello de autores como Vegecio, Polibio y Frontino, de los que ocasionalmente traduce largos textos- contribuye a superar lo que, a su juicio, es una debilidad humana pues el cristianismo "identifica la felicidad suprema con la humildad y con el desprecio por las cosas mundanas" ${ }^{\prime 21}$.

Así, implícitamente, contempla la historia como degenerativa. Por ello, propone volver a los modelos de antaño donde se premiaba la honradez y la virtud. Esto entraña una visión idílica y voluntarista de tales cuestiones y de la época considerada cuando el retorno al mundo clásico trae consigo, paradójicamente, una visión imperialista e inapropiada para el humanismo del uso de las Fuerzas Armadas. Roma fue una ciudad-Estado, como lo era también Florencia, de modo que lo que fue útil para Roma puede serlo igualmente para Florencia, cuya política y papel en el mundo de esta forma apoya.

Además, hay un hecho cierto e incontrovertible, los romanos fueron derrotados por unos ejércitos bárbaros que al hacerlo se mostraron superiores a aquellos. Recordando al propio Maquiavelo, no hay juicio más justo que el de los hechos. Además, una estrategia sostenida por mucho tiempo, como señala

${ }^{20}$ Carl Von Clausewitz. De la guerra T. I., Madrid, Ministerio de Defensa, 1999, p. 144.

${ }^{21}$ Félix Gilbert, op. cit, p. 37. 
Clausewitz dentro de su apuesta por la lógica dialéctica de la guerra, se ve siempre finalmente superada.

Es anecdótico, pero en mi condición también de marino resulta necesario referirlo. Sugiere Maquiavelo, desde un cierto simplismo, que un general de mar es más fácil de adaptar a tierra, pues ya no debe preocuparse de los vientos ni del agua. Uno de tierra, en el mar se encontrará en condiciones que no conoce y por tanto lo es menos. Pero Andrea Doria es un ejemplo de lo contrario pues fue Condottiero y no se embarcó hasta los 46 años de edad donde alcanzó notorios éxitos navales como, por ejemplo, Lepanto.

\section{Maquiavelo y la milicia ciudadana}

Maquiavelo puso en relación los cambios que se estaban produciendo en la organización militar y los que se estaban produciendo a nivel político y social. Así, habíamos señalado antes como, adelantándose a Max Weber, reclamaba para el Estado el monopolio de la violencia legítima, mientras consideraba impropio de una persona digna el recurso a la violencia privada. Y es que, para el florentino,

"la guerra es un arte del que ningún hombre en ningún tiempo puede vivir, como particular, honradamente, correspondiendo ejercitarlo a la república y los reinos... No se puede considerar hombre bueno al que ejerce a una profesión que exige la rapiña, el fraude, la violencia y muchas condiciones que necesariamente lo hacen malo"22.

La guerra es algo que solo puede ser justificada como un acto de Estado y de la política. Queda así claro que la descalificación que hace de la profesión militar se realiza en el contexto del rechazo al ejercicio privado de la violencia, esto es a los mercenarios, a los condotieros, pues considera que "en la paz es despojado por ellos y en la guerra por los enemigos" 23 acusándoles de la ruina de la Italia en su época.

De estos, si son buenos en su oficio "no puedes fiarte de ellos porque siempre aspiran a su propia grandeza, sea oprimiéndote a ti que eres dueño suyo, sea oprimiendo a otros contra tus intenciones; pero si el capitán no es valeroso comúnmente causa tu ruina"; y concluye: "la república ha de mandar a sus ciudadanos"24.

Tal y como dice en El arte de la guerra, "las armas en manos de sus ciudadanos no podían convertirlos en tiranos, sino las malas instituciones del

\footnotetext{
${ }^{22}$ Maquiavelo, El arte de la guerra. Obras politicas de Nicolás Maquiavelo, op. cit., p. 112.

${ }^{23}$ Maquiavelo, El Príncipe. Madrid, Unidad Editorial, 1999, p 61.

${ }^{24}$ Ibidem, pp. 61-62.
} 
gobierno que subyugan a la ciudad; y si tenían un buen gobierno, no tenían que temer sus armas" 25 .

No obstante, la propuesta de Maquiavelo se vio destrozada precisamente por las armas españolas en la toma de la localidad toscana de Prato (1512). Este fue un ejemplo de la llamada Furia española que dejó en torno a 4000 muertos, siendo el preludio de lo que había de suceder con las más relevantes ciudades italianas durante el siglo XVI. Tal cosa, además, ya se había visto antes en las batallas de Morat y Nancy (1476), batallas que hacían prever el destacado papel al que estaba llamada la Infantería.

La milicia florentina fue incapaz de responder mínimamente a una Infantería española que solo se encontraba apoyada para el asalto por dos cañones. La caída de la ciudad fue una catástrofe para Florencia. La República, de la que Maquiavelo era secretario e impulsor de la reforma militar que estaba acometiendo, cayó a consecuencia de ello, perdiendo él su empleo y marchando al destierro.

La razón de este fracaso pudo estar en la bisoñez de las tropas, el encontrarse estas mal dirigidas o su falta de adiestramiento, pero lo cierto es que no fueron mínimamente capaces de afrontar a la Infantería española y la derrota fue rotunda. Puede inferirse de todo ello, por tanto, y en términos marxianos, que aún no se daban las condiciones objetivas para implementar este tipo de forma de hacer la guerra. Esta sólo sería posible de la mano del pensamiento romántico.

En fin, la derrota de la República de Florencia, que había asumido los postulados de Maquiavelo a favor de una milicia ciudadana precisamente a manos de sus tan denostados mercenarios, no impidió que en la Ilustración Rousseau en La nueva Eloísa y en diversos escritos ${ }^{26}$, retomase la idea del florentino insistiendo en que todos los ciudadanos debían ser soldados no por profesión sino por deber ${ }^{27}$.

Y es que, tras la Ilustración, el concepto de Nación política y su lealtad -de naturaleza cuasi religiosa- el patriotismo, surge de la revolución y se consolida en el romanticismo decimonónico rellenando el hueco ideológico que propició el fracaso de Maquiavelo. Cubrirá así el espacio de lo trascendente, toda vez que su aparición sirvió a la espiritualización de las causas y a la adopción de rasgos caballerescos por las multitudes; el patriotismo se convertiría ahora en el nuevo elemento vertebrador de las Fuerzas Armadas, contribuyendo a la cohesión de sus miembros y a la eficacia de la fuerza. 114.

${ }_{25}$ Nicolás Maquiavelo, El arte de la guerra. Obras politicas de Nicolás Maquiavelo, op. cit., p.

26 J.J. Rousseau, Escritos sobre la paz y la guerra, Madrid, Centro de Estudios Constitucionales, 1982, p. 66.

${ }^{27}$ C.F. Friederich, El Hombre y el gobierno, Madrid, Editorial Tecnos, 1968, p. 452.

Araucaria. Revista Iberoamericana de Filosofia, Politica, Humanidades y Relaciones Internacionales, año $22, \mathrm{n}^{\circ} 44$. Segundo semestre de 2020. Pp. 359-385. ISSN 1575-6823 e-ISSN 2340-2199 https://dx.doi.org/10.12795/araucaria.2020.i44.17 
Las armas de fuego dotan de un componente igualador en tanto que no requieren de la destreza y nivel de preparación que las blancas. Son por ello, al mismo tiempo, instrumentos de revolución social. La entrada de los pueblos en la liza, no obstante, tenderá a la ampliación de los objetivos políticos y las absolutizará, toda vez que cuando se moviliza al pueblo mediante la propaganda, es muy difícil conseguir moderación. Esto, unido a la expansión de los límites del campo de batalla como consecuencia de la Revolución Industrial y del Transporte tenderá a hacerlas totales.

Para contradecir a Maquiavelo tenemos prácticamente a todos los países que cuentan con milicias hoy en Oriente Medio y tienen problemas con ellas. Bien es cierto que la mayoría no tiene un nivel de institucionalización adecuado, pero es más alto que el que existía en su época. A reseñar también cómo las guerras que emprenden los militares son, con mucho, menos cruentas que las desarrolladas por otros colectivos porque "en la guerra vale más la disciplina que la impetuosidad"28 y la fuerza es direccionada y modulada de modo acorde a los fines que se pretenden conseguir. La profesionalidad hace un uso tasado de la violencia.

El aprecio de Maquiavelo por la Infantería es, al mismo tiempo, una señal de reconocimiento del papel de pueblo en los conflictos, pero también escenifica el rechazo hacia los mercenarios por el peso que tenía la Caballería en este tipo de tropas.

\section{Los mercenarios}

Otra cuestión recurrente en el trabajo de Maquiavelo es la problemática de los mercenarios a los que, como decíamos, llega a culpar de la ruina de Italia. Pero los mercenarios siempre han estado presentes en la guerra y aún hoy lo hacen. El artículo 47 del Protocolo I de la Convención de Ginebra ${ }^{29}$ define como mercenario a quien:

“a) Haya sido especialmente reclutado, localmente o en el extranjero, a fin de combatir en un conflicto armado.

b) De hecho, tome parte directa en las hostilidades.

c) Tome parte en las hostilidades animado esencialmente por el deseo de obtener un provecho personal y al que se haga efectivamente la promesa, por una Parte en conflicto o en nombre de ella, de una retribución material considerablemente superior a la prometida o abonada a los combatientes de grado y funciones similares a las fuerzas armadas de esa Parte.

d) Que no sea nacional de una Parte en conflicto ni residente en un territorio controlado por una Parte en conflicto.

${ }^{28}$ Maquiavelo, El arte de la guerra. Obras políticas de Nicolás Maquiavelo, Op. Cit., p. 303.

${ }_{29}$ OR7-004, El Derecho de los Conflictos Armados. Tomo III, Doctrina del Ejército de Tierra, noviembre 2007, p. 75.

Araucaria. Revista Iberoamericana de Filosofia, Politica, Humanidades y Relaciones Internacionales, año $22, \mathrm{n}^{\circ} 44$. Segundo semestre de 2020. Pp. 359-385. ISSN 1575-6823 e-ISSN 2340-2199 https://dx.doi.org/10.12795/araucaria.2020.i44.17 
e) No sea miembro de las Fuerzas Armadas de una Parte en conflicto.

f) No haya sido enviada en misión oficial como miembro de sus fuerzas armadas por un Estado que no es Parte en el conflicto" ${ }^{\text {"30. }}$

Para substituirlos, los países occidentales han recurrido a contratistas privados para reforzar sus capacidades. Estas empresas han recibido el nombre de Compañías Privadas de Seguridad (CMP):

\begin{abstract}
"una empresa privada comercial y legalmente establecida, que se beneficia de ofrecer servicios que involucran el uso 'potencial' de fuerza de una manera sistemática y por medios militares, y/o por la transferencia de este potencial a clientes a través del entrenamiento militar diverso y otras actividades como ayuda logística, procuramiento de equipo y colección de inteligencia. Es un potencial porque la presencia mera de una CMP puede disuadir a agresores de considerar el uso de fuerza como un medio para lograr sus objetivos. El rol de la CMP no necesita siempre involucrar el uso potencial o activo de fuerza, ellas pueden dirigir sus actividades también al incremento de las capacidades militares y de seguridad de sus empleadores" ${ }^{\prime 31}$.
\end{abstract}

La cuestión es que los requisitos exigidos para calificar jurídicamente una actividad como mercenaria son muy estrictos lo que sitúa a los miembros de las compañías privadas de seguridad en una zona jurídicamente nebulosa. Se mezcla y confunde, pues, en un mismo espacio, lo público, lo privado, lo militar y lo civil, creándose actores híbridos y redes informales que favorecen la criminalidad.

Más aún, y por mostrar la vigencia del pensamiento de Maquiavelo. Una tendencia evidente en todos los enfrentamientos armados hoy en día es la diversificación de la violencia, de modo que los conflictos proporcionan un marco favorable y pueden servir como detonante para muchas otras formas de violencia organizada y no organizada.

La compleja mezcla de actores violentos que tienen los conflictos del siglo XXI se ve a menudo complementada con bandas mafiosas y especuladores que usan la violencia criminal para obtener ganancias materiales, explotar las posibilidades ofrecidas por las economías de guerra ${ }^{32}$ y obtener financiación para sus actividades. Una situación que, como puede verse, no parece ser muy lejana a la Italia del siglo XVI.

\footnotetext{
30 Manuel Cesar Arienza Fernández, Transnacionalización y privatización de la Defensa, Monografía IX Curso de Estado Mayor, 2008, p. 14.

31 Carlos Ortiz, "Regulando Compañías Militares Privadas: Estados y el creciente negocio de la seguridad privada" [en L. Assassi, D. Wigan and K. van der Pijl (eds.), Global Regulation. Managing Crises after the Imperial Turn, University of Sussex, 2004], p.206.

${ }^{32}$ Ekaterina Stepanova, "Un patrón para el estudio de los conflictos armados." [en VV.AA. Una mirada al mundo del siglo XXI. Ministerio de Defensa, 2008], p. 43.
} 
Una figura, casi una institución, que se repite constantemente en los Estados fallidos, en las guerras de desintegración, es la de los señores de la guerra, una suerte de nuevos condottieros, líderes dotados de medios militares, cabezas a veces de estructuras tribales que, ante el colapso del Estado, ejercen el poder sobre una porción del territorio, como resultado de la concurrencia de diversos planos de conflicto. En su área de dominación utilizan la delincuencia para la financiación de sus actividades, incrementar su poder y lucro personal y se protegen con las armas ${ }^{33}$. Como vemos, se trata de la misma lógica que se daba en la Italia de Maquiavelo, en la que también interferían las potencias de la época.

Otro de los problemas que, como se ha visto, apuntaba Maquiavelo es qué hacer con las tropas una vez llegada la paz, cómo evitar que se vuelvan contra quien los contrató. Por eso, “en la guerra debe tomar a los jefes de entre los ciudadanos, y en la paz hacerles retornar a sus habituales labores " 34 . Ya no resulta rentable mantenerlas y hay que proporcionarles opciones. Es lo que hoy en día se llama en terminología anglosajona Security Sector Reform (SSR), la reforma del sector de seguridad, actividad que se realiza con vistas a ofrecer una salida a los militares y evitar que condicionen o perturben los procesos de paz.

La violencia, una vez desencadenada, genera vida propia dando lugar a grupos parasitarios cuyas rentas económicas y poder dependen de su continuación ${ }^{35}$. Al deshacerse las estructuras de los Estados fallidos, los miembros de las Fuerzas Armadas se constituyen en elementos de poder incorporándose a los cuerpos de seguridad privada y a los ejércitos mercenarios o contribuyen al poder de los señores de la guerra, desestabilizando aún más el sistema. Por eso es preciso darles una salida.

El ejemplo de Colombia con la guerrilla es pertinente, pero también vale para los países de la órbita de la antigua URSS, donde el poder se construía sobre un triángulo formado por líderes políticos, los partidos comunistas y las Fuerzas Armadas. Al desaparecer los partidos comunistas, las Fuerzas Armadas se alinearon con el poder político. La acción de la OTAN entonces posibilitó el tránsito de estos países hacia el modelo democrático occidental.

33 Miguel Alonso Berro, "Los Estados fallidos". [en VV.AA. Cuaderno de Estrategia núm. 120/2002], p. 215.

${ }^{34}$ Maquiavelo, El arte de la guerra. Obras políticas de Nicolás Maquiavelo. op. cit., p. 114.

35 Miguel Alonso Berro, op. cit., p. 215. 


\title{
Relaciones entre fuerzas armadas y sociedad civil
}

Según se ha visto, Maquiavelo ${ }^{36}$ en su trabajo trató política y guerra como un todo indivisible, anticipándose de este modo a Clausewitz por su carácter de instrumento o función.

Es más, sostiene la idea de que no debe existir discordancia entre el mundo civil y el militar. De la misma se deriva la imperfección con la que se hace la guerra en tanto que continuación de la política, porque el mundo civil debe ser continuación del mundo militar o, mejor aún, este de aquel. De ahí su propuesta de regreso al pasado romano donde existía esa armonía. El aparato militar sirve así también de escuela de virtudes cívicas.

La propuesta de Maquiavelo de volver a la antigüedad clásica y a la equivalencia entre soldado y ciudadano supone un tiempo de refuerzo y rearme moral que contribuye a la legitimación del oficio de las armas. Es, como antes decíamos, un estado ideal, una ensoñación sorprendente precisamente en Maquiavelo, pues con ese retorno se pretende nada menos que:

\begin{abstract}
"Honrar y premiar la virtud, evitar desdeñar la pobreza, apreciar los hábitos y órdenes de la disciplina militar, obligar a los ciudadanos a amarse los unos a los otros, vivir sin banderías, preferir los asuntos públicos a los intereses privados" 37 .
\end{abstract}

Los ejércitos profesionales comenzaron a aparecer en el Neolítico ligados a la existencia de excedentes de producción que pudieran mantenerlos. Usando palabras de Walter Bagehot, "la civilización empieza porque el principio de la civilización es militar" ${ }^{38}$. Solo el genio de la antigua Atenas y de la vieja Roma supieron crear, respectivamente, las condiciones filosóficas y jurídicas precisas para que el poder político y el poder militar se diferenciaran ${ }^{39}$, conservándolo conexo e interrelacionado.

El Renacimiento incorpora el desarrollo del aparato del Estado y la creación de ejércitos permanentes profesionales dependientes de la corona. $\mathrm{Y}$ es que la idea del Estado como ente soberano tardó mucho tiempo en configurarse. Se trata de una idea consustancial al Renacimiento cuya formulación puede atribuirse a Maquiavelo -lo Stato-, si bien la doctrina de la soberanía estatal solo queda perfilada en el trabajo de Bodino, a finales del siglo XVI. Surgen términos como State en Inglaterra y État en Francia, que empiezan a emplearse en su sentido moderno, es decir, cuando

\footnotetext{
36 J.A. Fernández-Santamaría, Juan Ginés de Sepúlveda: la guerra en el pensamiento político del Renacimiento, Madrid, Centro de Estudios Políticos y Constitucionales, 2007, p. 11.

${ }^{37}$ Maquiavelo, El arte de la guerra. Obras politicas de Nicolás Maquiavelo. Op. Cit., p. 110.

${ }^{38}$ Walter Baguehot, Phisic and Politics. Beacon Press, Boston, 1956, p 32.

${ }^{39}$ Antonio Carro Martínez. El Estado y las Fuerzas Armadas. Colección informe. Disponible en: http://www.mpr.gob.es/servicios/publicaciones/vol01/
} 
la idea de un gobernante que intenta conservar su Estado fue dando paso a la del Estado como una entidad independiente que ese gobernante tiene que proteger.

El papel de los ejércitos es fundamental en la configuración institucional de la nueva organización emergente convirtiéndose en instrumento de dominación y control. Fundir un cañón de valor militar requería un gran despliegue de medios y una organización solo al alcance de la corona ${ }^{40}$. La artillería favorecerá de este modo a los grandes Estados que pueden costearla frente a los pequeños. En palabras de Tilly, "la guerra hace al Estado y el Estado hace la guerra"41.

El personaje principal de El arte de la guerra, Fabrizio Colonna, sostiene, no obstante, que la artillería no es precisa por ser lenta y difícil de mover:

"la artillería tiene un mayor uso en el ataque que en la denfensa, y como las milicias romanas tenían una gran capacidad de ataque la artillería podría haberse utilizado para reforzar los métodos romanos de hacer la guerra en lugar de invalidarlos" $"$.

Estaba equivocado.

La difusión de las armas de fuego y la necesidad de un menor adiestramiento, como se ha visto, acercó el pueblo a los ejércitos y reforzó el creciente papel del rey en detrimento de la aristocracia ${ }^{43}$. Como Tilly apunta: "Después de todo, los impuestos, fueron el medio principal mediante el que los forjadores de estados, en el siglo XVI y después, financiaron la expansión de sus ejércitos que fueron a su vez el principal instrumento para establecer el control en sus fronteras, ampliarlas, defenderlas frente incursiones externas y asegurarse la prioridad en el uso de la fuerza dentro de ellas. Y, a la inversa, las necesidades militares fueron a lo largo de estos siglos el incentivo principal para el establecimiento de nuevos impuestos y la regularización de los viejos" 44 .

La complejidad del manejo de este poder requirió de la progresiva aparición de una Administración militar que se adelantó varios siglos y ejemplarizó en todo tiempo a la Administración civil ${ }^{45}$. Elliot ${ }^{46}$ señala cómo la substitución de un rey guerrero como Carlos $\mathrm{V}$ por el sedentario Felipe II, rodeado de documentos en su despacho, simbolizó adecuadamente la

\footnotetext{
40 José A. Pizarro Pizarro, La guerra de Indochina punto de inflexión de la historia militar contemporánea. Tesis Doctoral, Madrid, Universidad Complutense de Madrid, 2008, p. 17.

${ }^{41}$ Charles Tilly, The formation of National states in Western. Europe Princeton, Nueva Jersey, EE. UU., 1977, p. 42., Miguel Ángel Ballesteros Martín, "La Estrategia de seguridad y Defensa". Monografía núm. 67 del CESEDE, Fundamentos de la Estrategia para el siglo XXI, p. 49.

${ }^{42}$ Félix Gilbert, $O p$. Cit., p. 33

${ }^{43}$ Federico Engels, Temas militares, San Sebastián, Equipo Editorial S.A., 1968, p. 19.

${ }^{44}$ Charles Tilly, The formation of national states in Western Europe, op. cit., p. 23.

45 Antonio Carro Martínez, Op. Cit.p. 20.

${ }^{46}$ Charles Tilly, Coerción, capital y los Estados europeos 990-1990, op. cit.
} 
transformación del Imperio español, al pasar de la era del conquistador a la del funcionario.

Fuerzas Armadas y Estado fueron en la práctica ideas yuxtapuestas, al menos hasta finales del siglo XVIII. Cuantitativamente, en este periodo el número de militares era muy superior al de los miembros de cualquier otro componente del Estado. Ello obligaba a inversiones que comprometieron más de la mitad -y, en ocasiones, hasta dos terceras partes-del presupuesto nacional de los Estados ${ }^{47}$.

El poder del Estado era prácticamente el poder de sus ejércitos. Simultáneamente, la expansión de estos comenzó a eclipsar al armamento disponible por las fuerzas interiores, estableciéndose una distinción clara y que no existía previamente, entre "interior" y "exterior" fortaleciéndose el vínculo entre guerra y acción del Estado haciendo válida la definición de Max Weber: "el Estado es una comunidad humana que se arroga (con éxito) el monopolio del uso legítimo de la fuerza física dentro de un territorio dado"48. El rechazo de Maquiavelo a la violencia no ejercida por las autoridades legítimas y su equiparación al bandidaje encaja plenamente en la lógica weberiana.

Maquiavelo se retrotrae al Imperio romano y, con ello, a un tiempo en que los términos ciudadano y soldado eran mutuamente intercambiables. Esta tradición la recupera la Revolución Francesa con su célebre Ley Carnot: "Los jóvenes pelearán; los hombres casados forjarán las armas y transportarán abastos; las mujeres harán tiendas y vestidos y servirán en los hospitales; los niños convertirán telas viejas en hilos; los ancianos se harán transportar a la plaza pública y encenderán el valor de los combatientes, predicarán el odio contra los reyes y la unidad de la república".

El Servicio Militar Obligatorio fue el reconocimiento explícito de que las guerras se entablaban de acuerdo con objetivos nacionales y, a juicio de autores como Anthony Giddens, ayudó al proceso de implantación del sufragio universal. Un ejército de reemplazo es más fácilmente desmovilizable que uno profesional, su costo y peso político es inferior, solventándose los problemas que Maquiavelo anticipara.

El propio Maquiavelo insiste en señalar al líder político que debe mantener buenas relaciones con el pueblo, del que debe procurar ser amado; y también implicarse directamente en los asuntos militares, dos de los extremos del triángulo clausewitziano. Y entre el pueblo y las Fuerzas Armadas, desde su perspectiva, se debe buscar la identidad y confluencia a través de milicias ciudadanas.

47 VV. AA., Aspectos de los conflictos, Documento de Trabajo Departamento de Estrategia. X Curso de Estado Mayor, Escuela Superior de las Fuerzas Armadas, 2008.

${ }^{48}$ Charles Tilly, Coerción, capital y los Estados europeos 990-1990, Ibídem. 


\section{El surgimiento de la razón de Estado}

Maquiavelo habla de "un arte del Estado" y sienta las raíces del concepto, pero su concreción práctica se alcanza en la Francia de Richelieu, quien, paradójicamente, es el padre espiritual de Bismarck. De este crisol emerge la geoestratégica "razón de Estado" como la última razón del rey; el nombre se lo daría Giovanni Botero. La máxima expresión de la razón de Estado será la guerra. La política dejaba de significar ante todo el arte de gobernar una comunidad humana conforme a justicia y razón y se transformaba en el modo de preservar el Estado, tanto en su carácter de dominio sobre los súbditos como en las relaciones de este con otros Estados ${ }^{49}$.

Estamos, en palabras de Foucault, en una racionalidad específica y secularizada en el arte de gobernar que no tiene que respetar el orden general del mundo ni tampoco del orden religioso, por más que aspire a servirlo. Encarna una "ética finalista y teleológica" que debe aplicarse de acuerdo con la fuerza de un Estado que busca su expansión y perpetuación. El dilema que encarna gira en torno a la moralización del poder.

Por eso Maquiavelo aseveraba que el príncipe, no pudiendo ser temido y amado $^{50}$ simultáneamente, debe ser más temido que amado pues el primer sentimiento es más seguro y "no es razonable que quien está armado obedezca de buen grado a quien está desarmado" 51 . Al Capone lo expresaría diciendo que "se consigue más con una palabra amable y una pistola que con una palabra amable" 52 .

La conclusión de los críticos idealistas sobre la obra de Maquiavelo es que la combinación de las enseñanzas maquiavélicas y la herejía es el ateísmo. Tácito, el tacitismo, se convierte en el ámbito español en el modelo a seguir para refutar al tiempo que incorporar el pragmatismo implícito a las ideas de un Maquiavelo del que resulta forzoso abominar.

Dada la finalidad eminentemente práctica -la conservación y aumento del Estado-, sus cultivadores se alejaron del razonamiento especulativo para concentrarse en los casos prácticos, "históricos", buscando reglas de experiencia sobre las que hacer analogía. Con ello, la principal regla que enseñaba la razón de Estado era que no existía una sola, sino varias; y que, si se interpretaban mal, se caía en lo que Saavedra Fajardo llamó "hipocondría de la razón de Estado", una suerte de deriva que hace que a un despropósito le siga otro aún mayor.

Eso hará que a la larga la razón de Estado consolidara un significado un tanto reduccionista, que hace de ella poco menos que un manual para gobernantes sin escrúpulos; y esto acababa por dotarla de mala fama. El quid

\footnotetext{
${ }^{49}$ Enric Mallorquí- Rucadella (Editor), Política y Razón de Estado en las letras del Siglo de Oro, Revista ehumanista, volumen núm. 31/2015.

${ }^{50}$ Maquiavelo, El Príncipe, Madrid, Editorial Millenium, 1999, p. 81.

${ }_{51}$ Maquiavelo, El Príncipe (Comentado por Napoleón Bonaparte), op. cit., p. 105.

52 Benjamín R. Barber, El imperio del miedo, Ediciones Paidós Ibérica S.A., Barcelona, 2004, p. 23.
} 
de la razón de Estado, así vista, venía a situarse en encontrar el adecuado grado de dureza y maquinación para el logro de objetivos buenos para la comunidad. Más aún, de la razón de Estado se podía evolucionar sin solución de continuidad al absolutismo ${ }^{53}$.

De ello resulta una paradoja: la razón de Estado de raíz maquiavélica era la resultante de un complejo de naturalismo, voluntarismo y racionalismo que se ha ido desarrollando con ganancia aparente del último para verse al final frustrado pese a desembocar necesariamente en el darwinismo político ${ }^{54}$. La totalización racional ha acabado por significar el triunfo del voluntarismo, en el sentido filonazi de la obra de Leni Riefenstahl El triunfo de la voluntad.

Así, la razón de Estado se ha ido convirtiendo paulatinamente en "pasión de Estado", en un escenario marcado por la guerra de los Treinta años, Napoleón, la guerra franco-prusiana o las dos Guerras mundiales del siglo XX. Como decía Saavedra Fajardo, se invoca la paz, pero se hace la guerra, locuras de Europa. La razón de Estado ha sufrido un reciente descrédito puesto que se considera contradictoria con el Derecho Internacional y el Gobierno constitucional. Pero, con todo y aún hoy, sigue viva ${ }^{55}$.

\section{Ética y liderazgo político}

Los modelos de héroes que oferta Maquiavelo los toma del mundo clásico: Alejandro Magno, Aníbal, Escipión, el Africano, etc. Son gente exitosa más que virtuosa, más conocidos por su valentía que por su honradez, como no podía ser de otra manera pues: "Cuando un príncipe tiene que obrar conforme a la índole de los brutos, los que ha de imitar, según el caso, son el león y la zorra. El ejemplo del león no basta porque no se preserva de los lazos y la zorra sola no es suficiente, porque no puede librarse de los lobos. Es necesario ser zorra para conocer los lazos, y león para espantar a los lobos; pero los que toman por modelo al último animal no entienden sus intereses" ${ }^{56}$. El líder aúna así la doble naturaleza del centauro Quirón, bruto y hombre simultáneamente

No es gente siempre violenta, sino solo cuando conviene. El príncipe debe ser capaz de "no alejarse del bien, pudiendo hacerlo, sino saber entrar en el mal, si es necesario"57. La propuesta de Maquiavelo por la violencia es así una opción racional y de elección. Y se suma a un tipo de liderazgo sumamente

${ }^{53}$ Enric Mallorquí- Rucadella (Editor), Politica y Razón de Estado en las letras del Siglo de Oro, Revista ehumanista, volumen núm. 31/2015.

${ }^{54}$ María Teresa Cid Vázquez "De la razón a la pasión de Estado: locuras de Europa" [en Enric Mallorquí- Rucadella (Editor), "Política y Razón de Estado en las letras del Siglo de Oro", Revista ehumanista, volumen núm. 31/2015].

55 Ibidem.

${ }_{56}$ Maquiavelo, El Príncipe, Madrid, Unidad Editorial, 1999, p. 89.

57 Viroli, Maurizio, Nicolas Maquiavelo, Tusquets editores, 2004, p. 137. 
proactivo; se encuentra íntimamente ligado a la acción pues, aunque la fortuna sea impredecible, la virtu del príncipe puede domeñarla. Así, es mejor "ser impetuoso que circunspecto"58. Maquiavelo cultiva la osadía.

La clave de su modelo de liderazgo se encuentra en una suerte de trinidad formada por la Fortuna, la oportunidad -el savoir faire - lo que el florentino llamaba la virtù.

En este sentido escribiría "no debemos dejar nacer un desorden para evitar una guerra, porque acabamos no evitándola; la diferimos únicamente: y no es nunca más que con sumo perjuicio nuestro"59, aunando así percepción, oportunidad y proactividad, una nueva trinidad. Napoleón la consideraba literalmente una regla básica de su conducta ${ }^{60}$.

Esta trinidad se contrapone a la otra trinidad de Clausewitz: el peligro, el azar y la incertidumbre; y a la que, en coincidencia con el germano, forman líderes políticos (el príncipe), el pueblo y las Fuerzas Armadas. Tenemos pues también en Maquiavelo las trinidades que más adelante identificaría Clausewitz en sus escritos.

Como se señala en El arte de la guerra, el general no tiene que librar todas las batallas que se le planteen -un error muy común-, sino aquellas necesarias para sus objetivos. Le es más interesante evitar que ser bombardeado, y preservar sus fuerzas, que bombardear al enemigo. Es preciso esquivar más que golpear, esto último es, pese a su vistosidad, secundario.

La definición de un buen liderazgo tiene dos acepciones una técnica y finalista y otra ética o de buena praxis. No obstante, a los líderes se les conoce por lo que hacen y no tanto por cómo lo hacen. Es decir, no se les exige tanto una perfección moral -lo que reduciría el espectro de líderes disponibles-como resultados prácticos.

Los ejemplos de los que nos dota Maquiavelo son claros: Alejandro y César Borgia o Fernando el Católico, que tal vez (o no) fuera ese "príncipe de nuestro tiempo, cuyo nombre no conviene mencionar, [que] predica continuamente la paz y lealtad, siendo en realidad enemigo de ambas; de hecho, sí hubiese observado tanto la una como la otra, habría perdido repetidas veces el prestigio y el Estado" ". La lógica política está secularizada y no se somete a nada salvo a la razón.

Es más, su propuesta política a veces parece que se asienta sobre el engaño por lo que se le tilda de inmoral, amoral o antimoral, pero Maquiavelo lo que hace realmente es definir una metodología y no entra en los concretos fines a los que esta sirve, salvo para pronunciarse por la unidad de Italia.

\footnotetext{
${ }_{58}^{5}$ Maquiavelo, El Príncipe, Madrid, Unidad Editorial, 1999, p. 119.

${ }^{59}$ Ibidem p. 32.

${ }^{60}$ Maquiavelo, El Príncipe (Comentado por Napoleón Bonaparte), Op. Cit., p. 167.

${ }^{61}$ Ibidem, p. 122.
} 
Así en El Príncipe sostiene:

"un príncipe debe tener muchísimo cuidado de que no le brote nunca de los labios algo que no esté empapado de las cinco virtudes citadas, y de que, al verlo y oírlo, parezca la clemencia, la fe, la rectitud y la religión mismas, sobre todo esta última" 62 .

Su ética es una ética finalista. Napoleón, en sus comentarios al Príncipe, ironiza sobre la preocupación ética que, con todo, se destila de algunos de sus juicios, censurándolo y tildándolo de infantil. Pero la apuesta del florentino es clara.

"Y en las acciones [de los príncipes]... se atiende a los resultados. Trate, pues, un príncipe de vencer y conservar el Estado, que los medios siempre serán honorables y loados por todos; porque el vulgo se deja engañar por las apariencias y por el éxito; y en el mundo sólo hay vulgo, ya que las minorías no cuentan sino cuando las mayorías no tienen donde apoyarse" ${ }^{\prime 3}$.

La cuestión es que el liderazgo es una construcción cultural ligada a la realidad y a los sucesos. La inconsistencia moral de los líderes, esto es, el desencaje entre su prédica y sus acciones, pese a lo que apunta Maquiavelo, les resta credibilidad y mina su desempeño, y aunque solo sea por esta razón, debe ser considerada, máxime en un tiempo en que resulta difícil escapar al escrutinio público ${ }^{64}$. "Tampoco se puede definir virtud el hecho de matar a los ciudadanos, traicionar a los amigos, y no tener ni palabra, ni piedad ni religión: de esta forma se puede obtener el poder, pero no la gloria" ${ }^{65}$.

Un ideal ético es una hipótesis de perfección moral. Maquiavelo ha hecho más visible la escisión siempre existente entre la ética de los individuos y la ética de los gobernantes. La ética de los individuos podría estar orientada por ciertos ideales de cualquier tipo, pero la ética de los líderes no puede estar orientada por unos principios a priori asentados sobre la bondad de las buenas acciones, es decir, no puede estar orientada por ideales personales y, al decir del florentino, imaginarios.

El príncipe a veces debía obrar para su preservación, en tanto que bien superior, "contra la fe, contra la caridad, contra la humanidad y contra la religión" "66 aunque sin reconocerlo nunca. Su proceder estaba dotado no pocas veces de una "piadosa crueldad".

$\mathrm{Y}$ es que, en el terreno de lo político, conceptos que en otro plano

${ }^{62}$ Ibidem, pp. 121-122.

63 Ídem.

64 Joanne B. Ciulla, "What is good leadership", Center for Public Leadership, Work Papers Center for Public Leadership, 2004, p. 6.

65 Maquiavelo, El Príncipe (Comentado por Napoleón Bonaparte), Op. Cit., p. 75.

${ }^{66}$ Maquiavelo, El Príncipe, Editorial Millenium,, 1999, p. 75. 
tienen una cierta significación, en este ámbito cobran un valor distinto como resultado de la lógica de transformación inherente al pensamiento de Maquiavelo. Las categorías bueno/malo, justo/injusto, no son operativas. Se muestran insuficientes como factor explicativo: "bien usadas pueden llamarse aquellas crueldades que se hacen para afianzarse en el poder"67. Por lo demás algo no muy lejano a lo sostenido por Mandeville: "Vicios privados, virtudes públicas" con lo que se expresa la divergencia entre fines individuales y colectivos.

John Stuart Mill, un utilitarista, se apercibió de la separación existente entre la ética individual y la propia de sus actos apuntada por Maquiavelo. Las intenciones o razones de un acto nos dicen algo de la moralidad de una persona, pero son los fines de una acción lo que nos indican la moralidad de esta. Con ello, a veces las personas armadas con las mejores intenciones y valores morales pueden conducir al grupo al desastre y los actos de quienes solo buscan el beneficio personal más egoísta, acabar por beneficiar al conjunto ${ }^{68}$. Como André Gide decía, con buenos sentimientos suele hacerse mala literatura.

La ética, así vista, debe ser realista. De este modo se separa lúcidamente un ejercicio ético que busca el bien propio y la moral personal de otro que busca el bien común. Pues, según el realismo político para el que la moral es un idealismo: "El ámbito apropiado de lo ético es privado. En el público no tiene nada que hacer. Lo moral y lo político son incompatibles y, por tanto, a quien ha de actuar en política le es forzoso prescindir de la moral"69. Estamos, una vez más, ante un debate aún no resuelto e intrínsecamente humano.

\section{Conclusiones}

La aportación de Maquiavelo a la problemática de la guerra es precursora y de primer nivel, adelantándose a Clausewitz y describiendo algunos de los paradigmas más relevantes de las Ciencias Militares. También se adelantó al propio Weber solicitando para el Estado -del que es, junto con Bodino, ideólogo- el monopolio de la violencia legítima.

Confianza, adiestramiento y disciplina son sus recetas básicas para los ejércitos. Estas se ven complementadas por la existencia de un mando único y la batalla decisiva en una guerra corta. Todo ello bajo el amparo de estructuras organizativas que facilitan la tarea.

No obstante, su culto al mundo romano es excesivo. La legión convertida nuevamente en el eje de todo (de organización, de combate, de reclutamiento,

\footnotetext{
${ }^{67}$ Viroli Manzio, Nicolas Maquiavelo, Tusquets Editores, 2004, p. 153.

68 Joanne B. Ciulla, "What is good leadership", Center for Public Leadership, Work Papers Center for Public Leadership, 2004, p. 6.

69 José Luis López-Aranguren, Ética y Política, Madrid, Ediciones Guadarrama, 1968, p. 163.
} 
etc.) no se adecuaba a los modelos y cultura de la época. Y las tácticas de combate que propugnaba difícilmente, como ya sucedió en el desastre de Prato -que propició su caída personal y aún la de toda la República de Florencia al auspiciar un modelo de Fuerzas Armadas, las milicias, no acorde a su épocatendrían una concreción práctica.

El ser derrotado por la Infantería explica su pobre valoración de la Artillería y las armas de fuego, no atisbando, pese a su perspicacia, a ver en toda su dimensión el cambio de modelo estratégico que se estaba produciendo. Y fueron los españoles - a cuya competencia militar no dispensa críticaprecisamente los que le derrotaron, hecho poco puesto en valor. Prato, con su paradójica importancia para el mundo de las ideas -la derrota enseña- es una batalla poco conocida.

Su poco afecto a la Caballería está en relación tanto con el papel que tiene el pueblo en la Infantería como con su rechazo a los mercenarios cuyos ejércitos se construyen sobre esta arma por la necesidad de adiestramiento que demanda.

Tampoco dio la importancia debida a las cuestiones económicas que el desarrollo de los nuevos ejércitos iba a traer aparejado y que forzarían la creación del aparataje estatal. Su propuesta de volver al mundo clásico -sus nuevas leyes de la guerra parecen ser las viejas leyes de la milicia romana ${ }^{70}$ es simplista y tampoco tiene sentido porque, como apunta Clausewitz, "cada tiempo tiene su forma peculiar de guerra... cada uno tendrá también su propia teoría de la guerra"71. Los problemas que plantea en su trabajo, como la mayor parte de las cuestiones heurísticas, se mantienen vigentes aún hoy.

Así, la cuestión de los mercenarios en el siglo XXI permanece inalterada cuando no se reformula en forma, por ejemplo, de Compañías Privadas de Seguridad. Estas permiten la intervención de los Estados en conflictos internacionales sin exhibir la bandera.

Al mismo tiempo emergen en los Estados fallidos una nueva figura, los conocidos como señores de la guerra que, a modo de modernos Condottieri, tratan de hacerse con el poder de modo personalista aunando, no pocas veces bajo sus personas, conflictos que incorporan distintos tipos de violencia (estatal, tribal, étnica, delincuencial, cultural, etc.) y actividades tanto lícitas como ilícitas en un maremágnum difícilmente diferenciable.

El fin de la llamada Guerra Fría ha traído consigo también el fin del Servicio Militar Obligatorio, que se atenía a la propuesta del soldado-ciudadano formulada por Maquiavelo. Una propuesta, por otra parte, demasiado prematura para su época. Esto, unido al énfasis en la tecnología, ha provocado la vuelta de

\footnotetext{
${ }^{70}$ Félix Gilbert, Op. Cit., p. 34.

${ }^{71}$ Carl Von. Clausewitz, De la guerra T II, Ministerio de Defensa, 1999, p. 331.
} 
la milicia profesional y los ejércitos permanentes, aunque el Estado, al menos en Occidente, conserve el monopolio legítimo de la fuerza.

El Servicio Militar, bien llevado, era una excelente escuela de ciudadanía que dotaba de mayor legitimidad a la acción de los ejércitos e implicaba a la sociedad en la Defensa garantizando la conexión entre Fuerzas Armadas y sociedad, actuando de escuela y reforzando su base: "los hombres bien disciplinados temen la ley, tanto armados como desarmados; y jamás causarán perturbaciones si no los provocan los jefes que se les da"72.

Los problemas de ética y eficacia se mantienen aún sin ser plenamente resueltos pese a su acomodo a la realidad cultural; la dialéctica entre el fin y los medios permanece inalterada. La razón de Estado, tan íntimamente asociada a las políticas de poder y al realismo político, explícita o implícitamente, sigue vigente en lo fundamental, pero también su crítica. Freund, a propósito de un escrito schmittiano, decía que el drama del pensamiento de Maquiavelo es que acababa negando la autonomía de lo político.

$\mathrm{Ni}$ siquiera un juicio a posteriori sobre un hecho -el ejemplo que se ha dado respecto de la guerra con el llamado ius post bellum- puede ser la solución al paradigma ético que se plantea. Cuando a un líder de la China moderna le preguntaron su parecer sobre la Revolución Francesa consideró prematuro pronunciarse. La historia va trocando en cada época lo bueno en malo y viceversa.

El hombre, recordando a Protágoras de Abdera, es el eje y la medida de todas las cosas, eso aún no ha cambiado; y la verdad, es difícil que lo haga. Somos en todo demasiado humanos.

${ }^{72}$ Maquiavelo, El arte de la guerra. Obras políticas de Nicolás Maquiavelo, Op. Cit., p. 110 y ss. 


\section{Referencias bibliográficas:}

Alonso Berro, Miguel, "Los Estados fallidos" [en VV. AA. Cuaderno de Estrategia núm. 120/2002].

Arienza Fernández, Manuel César, Transnacionalización y privatización de la Defensa. Monografía IX Curso de Estado Mayor, 2008.

Baguehot, Walter, Phisic and Politics. Beacon Press, Boston, 1956.

Barber, Benjamín R., El imperio del miedo, Barcelona, Ediciones Paidós Ibérica S.A., Barcelona., 2004.

Bauman, Zygmunt, Modernidad líquida, Buenos Aires, Fondo de Cultura Económica, 2006.

Bouthoul, Gaston, Tratado de Polemología, Madrid. Ediciones Ejército, 1984. Carro Martínez, Antonio, El Estado y las Fuerzas Armadas. Colección informe.

Disponible en: http://www.mpr.gob.es/servicios/publicaciones/vol01/

Ciulla, Joanne B., What is good leadership. Work Papers Center for Public Leadership.

Clausewitz, Carl Von, De la Guerra T.I y II. Ministerio de Defensa, 1999.

David, Charles-Philippe, La guerra y la paz, Barcelona, Icaria, 2008.

Díaz de Villegas, José, La guerra revolucionaria, Madrid, Ediciones Europa, 1963.

Engels, Federico, Temas militares., San Sebastián, Equipo Editorial S.A., 1968. Fernández-Santamaría, J.A., Juan Ginés de Sepúlveda: la guerra en el pensamiento político del Renacimiento., Madrid, Centro de Estudios Políticos y Constitucionales, 2007.

Fraga Iribarne, Manuel, Guerra y conflicto social, Madrid, Gráficas Uguina, 1962.

Friederich, C.F., El Hombre y el gobierno., Madrid, Editorial Tecnos, 1968.

Gilbert, Félix, "Maquiavelo: El Renacimiento del Arte de la Guerra" [en Paret; Peter (Edit.). (1992). Creadores de la Estrategia Moderna, Madrid, Ministerio de Defensa]

Glucksmann, André, El Discurso de la guerra., Barcelona, Editorial Anagrama, 1969.

Hermosa, Antonio, El Hombre tras los hechos. Ediciones Universitarias Athenaica, 2019.

Jiménez Pérez, Felipe, "El materialismo y la Paz" en El Catoblepas, Revista Crítica del presente. Núm. 28/2004.

Kaldor, Mary, Las nuevas guerras., Barcelona, Editorial Tusquets, 2001.

Luis López-Aranguren, José, Ética y Politica, Madrid, Ediciones Guadarrama, 1968.

Luttwak, Edward N., Parabellum. Torrejón de Ardoz, Siglo XXI de España Editores, 2005. 
Mallorquí-Rucadella, Enric (editor), Política y Razón de Estado en las letras del Siglo de Oro. Revista ehumanista, volumen núm. 31/2015.

Maquiavelo, El Príncipe (Comentado por Napoleón Bonaparte). Madrid, Ed. Espasa Calpe, 1993.

Maquiavelo, El Príncipe. Madrid, Editorial Millenium, 1999.

Maquiavelo, El Príncipe. Madrid, Unidad Editorial, 1999.

Maquiavelo, El arte de la guerra. Obras políticas de Nicolás Maquiavelo. Ed. librería de la viuda de Hernando y Cia., 1895.

Maquiavelo, El Príncipe. Espasa-Calpe.

Martínez Paricio, Jesús, "Aproximación al planteamiento teórico del liderazgo estratégico". Documento de Trabajo del Instituto Español de Estudios Estratégicos, 2020.

OR7-004. El Derecho de los Conflictos Armados. Tomo III. Doctrina del Ejército de Tierra, noviembre, 2007.

Ortiz, Carlos, "Regulando Compañías Militares Privadas: Estados y el creciente negocio de la seguridad privada", [en L. Assassi, D. Wigan and K. van der Pijl (eds). (2004). Global Regulation. Managing Crises after the Imperial Turn., University of Sussex]

Pizarro Pizarro, José A., La guerra de Indochina punto de inflexión de la historia militar contemporánea. Tesis Doctoral, Universidad Complutense de Madrid, 2008.

Rousseau, J.J., Escritos sobre la paz y la guerra. Madrid, Centro de Estudios Constitucionales, 1982.

Stepanova, Ekaterina, "Un patrón para el estudio de los conflictos armados". [en VV. AA. (2008), Una mirada al mundo del siglo XXI. Ministerio de Defensa.]

Tilly, Charles (comp.), Formation of national states in Western Europe. Princeton University Press, EE. UU., 1975.

Tilly, Charles, Coerción, capital y los Estados europeos 990-1990, Madrid, Alianza Editorial, 1992.

Tilly, Charles, The formation of National states in Western. Europe Princenton, Nueva Jersey, EE. UU., 1975.

Tortosa Blasco, José María, "La palabra terrorista" [en VV. AA. (2006). Afrontar el terrorismo. Gobierno de Aragón].

Villalba Fernández, Aníbal, "Evolución del pensamiento estratégico." Monografía del CESEDEN núm 99/2003.

Viroli, Maurizio, Nicolas Maquiavelo. Tusquets Editores, 2004. 
